\title{
PROCESOS CREATIVOS Y SU AFECTACIÓN TRAS LA COVID-19. VENTANA ABIERTA (2020), TRABAJAR CON CUERPOS FísICOS A DISTANCIA'
}

\author{
CREATIVE PROCESSES AND THEIR IMPACT AFTER COVID-19. VENTANA ABIERTA (2020), \\ WORKING WITH PHYSICAL BODIES AT A DISTANCE
}

Manuel Garzón Albarrán Universidad Complutense de Madrid, España ORCID: 0000-0002-3992-69|4 manuel.garzon.a@gmail.com

\begin{abstract}
(1) (8)
Resumen |Ventana Abierta $(2020)^{2}$ es una videocreación con vocabulario de danza realizada durante los primeros meses de pandemia, cuyo producto final se genera tras un proceso creativo ejecutado "a distancia" entre España y Paraguay. El método autoetnográfico permite aflorar los procedimientos de investigación, en este caso performativa, ensamblando teoría y experiencia. A través de la autoetnografía intentaré mostrar las adversidades vividas en el proceso creativo de dicha obra, para indagar sobre la afectación de la coyuntura sanitaria de la COVID-19 en los procesos creativos, así como plantear posibles adaptaciones que debe de poseer la nueva creación de danza "a distancia"; considerando que tratamos una corriente artistica que utiliza el cuerpo del intérprete como lenguaje y se hace necesaria la presencia del mismo para articular el discurso de su obra. Un trabajo entre cuerpos, que aún, no pueden tocarse.
\end{abstract}

Palabras clave: Procesos creativos, Ventana Abierta, Autoetnografía, Coreografía, COVID-19.

\section{Abstract |Ventana Abierta $(2020)^{3}$ is a video creation with dance vocabulary made during the first months of the} pandemic, the final product of which is generated after a creative process carried out "remotely" between Spain and Paraguay. The autoethnographic method allows research procedures to emerge, in this case performative, combining theory and experience. Through autoethnography, try to show the adversities experienced in the creative process of said work, to inquire about the impact of the health situation of COVID-19 in the creative processes, as well as, propose possible adaptations that the new creation must have dance "at a distance"; considering that it deals with an artistic trend that uses the body of the interpreter as a language and its presence is necessary to articulate the discourse of his work. A work between bodies, which at the moment cannot touch.

\footnotetext{
'Recibido/Received: | I/06/2021

Aceptado/Accepted: 18/06/2021

Ventaba Abierta (2020) es la primera obra de carácter audiovisual del Ballet Clásico y Moderno Municipal (BCMM) de Asunción (Paraguay), capitaneada por el maestro Miguel Bonnin, contando con la colaboración de la Companhia de Dança do Pantanal (Brasil). El estreno mundial se realizó el domingo 24 de mayo del 2020, insertado en el proyecto pedagógico "Nde rógape" ("En tu casa"), una guía didáctica del espectador del ballet, en formato de "revista" de carácter audiovisual, cuyo contenido recoge obras e investigaciones de ámbito histórico, técnico y estilístico de la danza. Su actividad acercó la danza a todos los públicos habilitando su reproducción online, gracias a las plataformas digitales de la Dirección de Cultura y Turismo de la Municipalidad de Asunción (Paraguay). La obra se puede disfrutar en los siguientes canales: <https://vimeo.com/422339093> y <https://www.facebook.com/CulturaAsu/videos/ventana-abierta/2455I8459846483>.

${ }^{3}$ Ventaba Abierta (2020) is the first audiovisual work of the Municipal Classic and Modern Ballet (BCMM) of Asunción (Paraguay), led by maestro Miguel Bonnin, with the collaboration of the Companhia de Dança do Pantanal (Brazil). The world premiere was held on Sunday, May 24, 2020, inserted in the pedagogical project "Nde rógape" ("At your house"), a didactic guide for ballet spectators, in the format of an audiovisual "magazine", whose content collects works and research in the historical, technical and stylis tic field of dance. His activity brought dance to all audiences by enabling its online reproduction, thanks to the digital platforms of the Directorate of Culture and Tourism of the Municipality of Asunción (Paraguay). The work can be enjoyed in <https://vimeo.com/422339093> and <https://www.facebook.com/CulturaAsu/videos/ventana-abierta/2455I8459846483>.
} 
Keywords: Creative Processes, Ventana Abierta, Autoethnography, Choreography, CoVID-19.

Cuando pensamos en la COVID-19 se nos vienen a la cabeza muchas palabras; entre ellas: enfermedad, fallecidos, bloqueo social, educación cerrada, economía en descenso, discursos políticos, oleadas, picos, $\mathrm{UCl}$ desbordadas, aeropuertos cerrados, etc., todas ellas con un significado negativo. Actualmente, en los meses que llevamos del año 2021, se podrían añadir a las anteriores: vacunas, bajada del porcentaje de muertes, toque de queda, controles PCR, nuevos planteamientos educativos, apertura parcial de eventos sociales, reactivación de la cultura, todas ellas con un aire más alentador. Sin embargo, aunque la pandemia ha determinado que cunda sufrimiento y temor en el mundo, debemos de señalar algunos aspectos positivos que también se han potenciado en estos tiempos, en concreto me refiero a arte y creatividad. Ambos son caracteres epistémicos del ser humano, que han estado presentes en estos meses y que no pueden caer en el olvido.

La relación entre COVID-19 y el arte es bastante estrecha, puesto que durante la pandemia se han potenciado las manifestaciones artísticas en múltiples formas y desde diferentes estatus. En todos sus diversos estilos se han encontrado nuevas formas de enviar, producir y consumir obras de arte, al mismo tiempo que se ampliaba la producción creativa mejorando el valor de un abanico de artistas, que abarcaba desde grandes profesionales hasta niños aficionados, cuyas obras de arte de "lápiz y papel" enviaban mensajes de ánimo a profesionales de la sanidad y a sus familiares enfermos, unos mensajes que promovían la positividad y generaban fuerza en la batalla.

Esta coyuntura parece haber propiciado un aumento del consumo del arte "en el hogar" y "desde el hogar", cuyos beneficios, según nos cuentan estudios de grandes instituciones como la OMS o la Unesco ${ }^{4}$, se han dirigido hacia dos caminos. Por un lado, hemos consumido arte en circunstancia de ocio, como estudio y/o formación profesional, así como hábito en el ámbito de lo social que se ha trasladado al hogar por el aislamiento, utilizando los medios de comunicación tradicionales junto a las nuevas plataformas digitales, que han tenido una expansión significativa. Por otro lado, se ha potenciado el valor terapéutico propio del arte, que ante esta situación ha ayudado a las afectaciones del virus, con una producción artística que endulzó las consecuencias de la enfermedad y ha aliviado la dureza del aislamiento. Este sendero, curiosamente, apareció instantáneamente y con un alto valor. En un abrir y cerrar de ojos, se desbordó la creatividad por las ventanas y los balcones de las casas, que funcionaron como megáfonos y plataformas publicitarias donde se exponían mensajes de fortaleza, positivismo y unión entre agentes, insertos en obras de arte de pequeño formato, creadas en la gran mayoría de los casos por niños y cuyo valor era infinito e indiscutible.

Como reflexión a esta situación, me atrevo a afirmar, que las obras de arte —siempre presentes en la historia de la humanidad - han tenido un papel protagónico en las vivencias del último año, ya sea como anestésico del día a día o reflejando a través de su

\footnotetext{
${ }^{4}$ Por su parte, la OMS realizó una rueda de prensa para mostrar un estudio realizado a gran escala donde, por primera vez, sugiere a los Gobiernos y a las autoridades a aplicar políticas que mejoren la colaboración entre los sectores sanitario y artístico. Para más información consultar: https://www.youtube.com/watch?v=6h9B9Pk-0K0; Fancourt, D. \& Finn, S, (2019). What is the evidence on the role of the arts in improving health and well-being? A scoping review (2019). OMS. ISBN 9789289054553
} 
contenido una situación social a la que no estábamos acostumbrados y que nos pilló por sorpresa. Del mismo modo, es muy significativo cómo los agentes sociales necesitamos al arte y su consumo en momentos extremos, donde los que, sin dudarlo, extendemos el brazo para hacerlo nuestro, disfrutarlo y devorarlo, quizás sin pensar cómo ha llegado a estar ahí o cómo se ha formado.

Dentro del campo de la danza, especialidad donde desarrollo mi trabajo docente, investigativo y de creación, la pandemia ha generado múltiples consecuencias afectando a su actividad completa. En esta esfera de efectismo incluyo la formación de estudiantes de danza, que han tenido que dejar de instruirse en algunas materias propias el diseño curricular como Pas de deux o Contact improvisation; técnicas y asignaturas propias de la práctica de danza cuya matriz se realiza en contacto directo entre dos o más personas. También, se ha visto afectado el consumo de obras de danza en infraestructuras sociales, como teatros, museos, salas, etc., puesto que el aislamiento impedía el desplazamiento, anexado a unas normas de distancia social y aforo que, una vez superada la etapa de confinamiento, no se procedió inmediatamente a la reapertura de dichos equipamientos. Esta situación ha atacado al ámbito laboral del propio campo y sus afluentes: bailarines, maestros, coreógrafos, pianistas acompañantes, docentes, diseñadores, productores, gestores, compañías, centros de formación, entre otros, que se han visto obligados a cesar su labor temporal o definitivamente, unos daños colaterales incalculables, incongruentes con el aumento del consumo del arte en el hogar que señalaba anteriormente. Sin duda, nos encontramos ante una paradoja que invita a la reflexión.

Tras esta breve mirada contextual, me atrevo a afirmar que, a priori, la COVID-19 sí ha afectado a la praxis de la danza profesional, como a su formación y entrenamiento, debido a que la práctica en compañía y su trabajo cuerpo a cuerpo ha sido cesado temporalmente, y todavía, sin la vacuna inoculada en todos los practicantes, se actúa con prevención en dicho ejercicio por miedo a la propagación del virus. Ahora bien, llegados a este punto donde hemos analizado las afectaciones de la vida de la obra de danza, es necesario abordar la etapa de su nacimiento para atender a la problemática desde todos sus ángulos; de este modo, planteo: ¿ha afectado la COVID-19 a los procesos creativos?

Para responder a este interrogante hay que echar un vistazo a las premisas que articulan una obra de danza, para así comprobar en qué fase pueden haber sido trastocadas. Antes de comenzar, nos encontramos con la premisa física propia del estilo, pues se presenta un lenguaje que, en sí mismo, necesita de un cuerpo mediante el cual fabricar y encarnar su actividad. Pues, como proclamaba Duncan (2016), una de las grandes personalidades de la coreología, sin cuerpo que se mueva, no puede existir danza, un cuerpo que debe de ser cincelado por el coreógrafo, en un acto efectuado mediante un esencial proceso creativo, donde se pauta el movimiento dancístico mediante el trabajo de conectar la acción cinética con el espacio escénico, para así, narrar un mensaje, cuyo discurso es insertado - por el mismo creador- en el cuerpo del intérprete con cada movimiento y tras cada gesto. 
Retomando las fases estructurales de los procesos creativos, señalaré que cada creación de danza se compone de una primera fase de investigación conceptual ${ }^{5}$, realizada en la privacidad del estudio y donde se nutre la idea planteada en el objetivo del acto comunicativo. Para realizar este proceso, se utilizan diferentes métodos de recogida de datos para perfilar los "elementos internos" y "elementos externos" 6 de la obra. En mi caso, concretamente, es en esta fase donde, a priori, se deciden los caracteres de la obra: número de intérpretes, contexto social, estilo estético de los diseños escénicos (ambientación), "elementos externos" (música, escenografía, elementos específicos que intervienen en el material coreográfico), asimismo, como la estructura de la obra y su duración. Desde mi experiencia, dado que esta fase se realiza en un contexto privado y personal, no ha sufrido gran afectación tras la llegada del virus, dado que la digitalización de documentos y su consulta era bastante común anteriormente gracias a las Tecnologías de la Información y la Comunicación (TIC).

Abordaré el caso concreto de Ventana Abierta (2020), al adentrarme en esta primera fase tuve que decidir cuál debía de ser el mensaje que enviara una obra que pretendía suscitar empatía y cuya finalidad era brindar ayuda social. En este sentido, la pandemia sirvió decisivamente de inspiración para la obra, puesto que decidí poder narrar los estados emocionales latentes en los meses de confinamiento, marcados por la falta de contacto de nuestros seres queridos, sin poder abrazar a nuestros padres, sobrinos y abuelos. Además, debía mostrarse la obligada conversión que sufrieron nuestras casas transformándose en todas las infraestructuras que componen la agenda semanal, contando con el centro de estudios, el trabajo, el gimnasio, el centro de ocio o incluso la panadería; una compleja adaptación de nuestros hábitos a las cuatro paredes del hogar. Para cerrar el ciclo de construcción del mensaje, comprendí que en aquel momento la cultura adquirió un valor simbólico de esperanza y positividad, cuyos valores debían verse reflejados en esta obra, concentrados en un mensaje optimista, enviado con una obra que se disfrutara a la vista. Dadas las circunstancias, el soporte digital era el más indicado para componer una videodanza en la que los intérpretes se ubiquen en el interior de sus viviendas reales, trabajando y ejecutando la danza pautada de una forma individual (en espacio) pero con estructura grupal (en la construcción de imagen) y una conciencia grupal (danzando a distancia con otros intérpretes condicionados por estímulos similares, tanto creativos como vitales).

En la segunda fase de los procesos creativos se encuentra el trabajo con todos los componentes del proyecto. Entre ellos, se incluyen los bailarines y el resto de los diseñadores o creativos. En este momento se expone la matriz del trabajo y se plantean unos objetivos por conseguir, cuya finalidad reside en la construcción de la obra de danza

\footnotetext{
5 Se aplica el término "planteamiento conceptual" a aquel proceso creativo que transita sobre un concepto desechando una dramaturgia principal. Dicha herramienta suele usarse en las creaciones coreográficas en forma de puzle (si posee varias escenas) o en el trabajo de un segmento coreográfico con un solo acto o única escena. Estas estructuras que componen el "planteamiento conceptual" pueden poseer subdramaturgias, puesto que deben de desarrollar sus discursos, que, unidos entre sí, permitan acceder al objetivo principal.

6 Señalo como "elementos internos" aquellos que forman parte del movimiento coreográfico, contando con la actividad de los gestos, movimientos dancísticos, códigos extraídos de la simbología referencial o de condensación u otros elementos que se insertan en igualdad de valor junto al cuerpo. Los "elementos externos" son el resto de los elementos que forman parte de la obra, cuyo contenido comunicativo complementa o potencia el mensaje enviado junto a los "elementos internos"; en esta sección contamos con la iluminación, escenografía, atrezo, indumentaria, música, textos, etc.
} 
compuesta por el conjunto de todos los caracteres decididos en la etapa anterior. En esta fase del proceso, todo el equipo trabaja al mismo tiempo, construyendo la obra en comunicación directa, debido a que en el proceso pueden ir apareciendo nuevas ideas, quizás más interesantes, o simples matices semióticos que redirijan la trayectoria tomada. Personalmente, en esta fase me gusta separar dos escenarios de trabajo: por un lado, se cuenta con el trabajo entre creativos y directores, donde se preparan los componentes que forman los "elementos externos" de la obra; mientras que, por otro lado, se plantea el trabajo creativo de los "elementos internos", un encuentro interrelacional directo entre coreógrafo e intérpretes realizado en el laboratorio de danza, para gestar el "material coreográfico" de la obra.

En la coyuntura de la COVID-19, el trabajo entre creativos (diseñadores de "elementos externos") y directores puede realizarse, en una primera instancia, en formato virtual, ya que la comunicación se realiza a través de la palabra para proceder a la puesta en común de ideas y mostrar el material de trabajo representado sobre el papel. Sin embargo, el trabajo creativo de movimiento realizado por el coreógrafo y los bailarines necesita de los cuerpos danzantes, cuya construcción se realiza uniendo el material físico, donde se ubica el trabajo técnico del estilo, la modulación de dinámicas, fuerzas, sensaciones y direcciones espaciales, junto al componente "alma", mediante el que se entretejen emociones, sensaciones, campos semánticos y experiencias y donde todos ellos se unen con una concreta aplicación de la semiótica escénica. Ante esta necesidad, ¿cómo plantear una creación donde coreógrafo e intérpretes se encuentran aislados?

En la producción de Ventana Abierta (2020), esta fase supuso un gran reto, debido a que el sistema metodológico tradicional perdía vigencia al no tener los cuerpos presentes, para así, cincelar el movimiento. Coreógrafo, director artístico, bailarines, asistente de coreografía, profesores de danza titulares de la compañía, director general de la compañía, cámaras y editor de vídeo, todos nos encontrábamos aislados y trabajamos conectados mediante videoconferencia. Esta novedosa situación hizo preciso el desarrollo de un método ad hoc, que se tenía que definir al mismo tiempo que se ponía en marcha. Supuso todo un reto por experimentar.

Una de las premisas claras que tuve que plantearme fue la necesidad de esbozar una obra que fuese flexible y adaptable a posteriores modificaciones, puesto que la distancia nublaba, en cierto modo, la intercomunicación y carecía del habitual control del proceso creativo con la misma precisión que en situaciones convencionales.

Otra de mis grandes preocupaciones residía en la unificación conceptual del mensaje por parte de los bailarines. Necesitaba ubicarlos emocionalmente en un mismo lugar; un punto de encuentro del fenómeno emocional común, para que, desde allí, pudieran lanzar un mensaje directo, con mucha "verdad", "libertad" y "honestidad", que fuese

7 Defino como "material coreográfico" a la sucesión de movimientos concatenados, estructurados según frases coreográficas, segmentos musicales o segmentos dramatúrgicos o de mensaje. También contamos con elementos de movimiento semiótico (códigos de simbología referencial o condensación) que puede adaptarse a otros elementos de movimientos propios del vocabulario técnico (como por ejemplo el vocabulario de la danza clásica).

${ }^{8}$ Los conceptos "verdad" y "libertad" se convirtieron en las premisas de las transformaciones de la obra escénica durante las vanguardias, centradas en exhibir el fenómeno emocional de los agentes, para así, personificar el objetivo de la obra eliminando a las dramaturgias idílicas anteriores. Manuel Gómez García, en su artículo Escritura teatral: de las vanguardias al futuro (200 I), desarrolla SHJ, 202I, I (I), pp. 225-233. ISSN: 2792-3967 
capaz de crear gran impacto en el espectador. Los estados emocionales seleccionados para el trabajo fueron: miedo, soledad, incertidumbre, rabia, desconfianza, dolor, irascibilidad, nerviosismo, sonambulismo, melancolía. Hablar de las emociones latentes en la pandemia facilitó la llegada de todos los componentes a este mismo objetivo?, puesto que, de una forma u otra, todos habíamos experimentado esos fenómenos emocionales.

Del mismo modo, otro gran conflicto se encontraba en la unificación del lenguaje del discurso, ya que contaba con poco tiempo de trabajo, estructurado en pocas sesiones virtuales. Para solventar este problema decidí partir del gesto y de acciones sociales comunes para todos, vinculadas con las emociones concretas que caracterizaban la pandemia. El método se centró en extraer el movimiento propio de estas acciones sociales y transformarlo para generar el "material coreográfico" primario. Entre las acciones seleccionadas se encontraban las siguientes: el abrazo, las caricias, el sendero trazado de la lágrima en la acción del llanto, los autogolpes de carácter emocional vinculados a la rabia y la impotencia y el movimiento torácico vinculado a la respiración y al circuito cardiovascular. Con este recurso pude trazar una conexión directa entre mi imaginario y el imaginario de los intérpretes, al mismo tiempo que encontré un modo de generar "material coreográfico" específico" ${ }^{10}$, formado por dinámicas, trayectorias, nivel de "esfuerzo" y carga emocional ya definidas (por las acciones sociales), que solo tenía que moldear en su adaptación a la coreografía.

Como tercera fase del proceso creativo, llegamos a la puesta en común de todo el trabajo realizado, con la finalidad de ensamblar cada elemento que será ubicado en su lugar específico y, así, cerrar el discurso final que compone la obra. Para este formato de videocreación, el material tenía que ser registrado en vídeo por cada uno de los intérpretes en soledad. Normalmente, esta fase es una de las más importantes de las videocreaciones, puesto que además del trabajo coreográfico del movimiento, existe un trabajo coreográfico de imagen, cuya fotografía debe de estar cuidada con esmero, ya que será la muestra al público de todo el proyecto.

Ante esta situación, donde no podía controlar el proceso de grabación, decidí emplear las condiciones sociales exigidas y sacarles partido en el plano semiótico, ofertando espacios coreográficos que debían de ser rellenados por la creatividad de los bailarines. Esto suponía ser flexible en la coreografía y receptivo con las propuestas, aceptando los aportes personales que brinden los intérpretes e incorporándolos a la obra. El método para realizarlo requería soltar el control de la grabación, de modo que, tras los

\footnotetext{
su teoría que defiende los conceptos de "verdad" y "libertad" como objetivos del texto teatral, utilizando estrategias que apelan a la razón y apelan al sentimiento emocional. Al mismo tiempo que funcionan como matriz de la historia del teatro, pautadas por el teatro griego, retomada por el romanticismo y aplicada en la era de las vanguardias del siglo $X X$. A estos valores se le suma "honestidad", entiendo que el mensaje emocional debe ser transmitido desde la vulnerabilidad y la transparencia de todos aquellos que forman parte del proceso creativo.

Tras el proceso creativos, los intérpretes exclamaron que dicho trabajo de ubicación emocional les resultó muy sencillo y tras breves directrices (del coreógrafo) entendieron perfectamente el lugar desde donde tenían que narrar su discurso; un discurso común que partía desde la esfera micro, y que conectaba con el colectivo. De este modo, la conexión entre todos los bailarines era tan directa que se llegaban a romper las distancias sociales.

${ }^{10}$ Durante las sesiones de creación, fue muy sencillo encontrar igualdad en la ejecución de movimiento entre todos los bailarines dando pautas como: "este abrazo es suave como si se abrazaras a tu abuela", "camina sin prisa como si fuese la madrugada de un sábado cuando no tienes que controlar el tiempo", "utiliza la mirada, como cuando miras la foto de tu mejor amigo de la infancia en una fiesta del colegio". Estas acciones ya poseen per se elementos de ejecución definidos.
} 
encuentros virtuales, cada intérprete se encargaba de fijar el material construido, libremente y en solitario, aplicando en privacidad las pautas técnicas e interpretativas propuestas en la sesión. Con esta libertad conseguí extender el tiempo de trabajo para acometer el perfeccionamiento del movimiento pautado en cada encuentro, con la intención de mejorar la praxis dancística y completar la exportación emocional del imaginario del intérprete al movimiento ejecutado.

Para concluir con el trabajo interpretativo, marqué una última pauta: al cerrar la conexión virtual con los bailarines, cada uno de ellos debía escuchar la pieza musical varias veces, mientras observaba fotografías de su familia y seres queridos, para, posteriormente, volver a la ejecución de la coreografía desde esa posición emocional. En este momento, cada intérprete decidía cuándo se había completado este trabajo, concluyendo con la grabación del "material coreográfico".

Para generar dicha grabación, se pautaron dos premisas importantes que garantizaran la honestidad del contexto y la calidad de la imagen fotográfica. La primera premisa requería de la naturalidad del escenario común del hogar. Se debía elegir una ubicación importante para el intérprete, en la que pasara el mayor tiempo posible o donde transitara aquellos momentos emocionales de alto impacto. Este escenario no debía ser modificado siguiendo parámetros estéticos propios que dañasen la autenticidad del documento. Como segunda premisa, se pauta que la cámara debe tener una distancia mínima de dos metros entre su posición y el intérprete, para así, garantizar el encuadre completo del cuerpo ejecutante. Otro elemento "libre" fue la utilización de cualquier ángulo fotográfico, no era necesario la frontalidad de la imagen. Con esta premisa se salvaban las problemáticas espaciales de las viviendas (habitaciones pequeñas o ubicaciones de estructura no rectangular). Además, así podía encontrar posibles perspectivas nuevas que habría encontrado por las limitaciones de la pantalla en la conexión online.

Como conclusiones de este trabajo, con el ejemplo de Ventana Abierta (2020), se demuestra cómo los procesos creativos pueden realizarse con éxito a pesar de la reformulación de las condiciones sociales derivadas de la pandemia. Sin duda, la presencia de la COVID-19 sí ha transformado la forma de dichos procesos, ya que se han tenido que modificar aquellas fases estructurales que necesitan de varios cuerpos interrelacionados. Como consecuencia y solución a esta problemática han aparecido nuevas circunstancias donde he podido hallar valores positivos, como la normalización del uso de las nuevas tecnologías insertadas en dichos procesos, contando con una fácil utilización de las TIC como plataformas asequibles para toma de datos y el planteamiento de nuevas herramientas de formación que están mejorando las Tecnologías de Aprendizaje y Conocimiento (TAC). Otro valor positivo reside en la cercanía instantánea que ofrecen la comunicación digital, pues como ejemplariza esta obra, se establece una conexión directa entre España y Paraguay, dos países ubicados a 9073 kilómetros, unidos a golpe de clic.

Finalmente, me gustaría resaltar el enfoque inspirador que los creadores hemos encontrado en las circunstancias de la pandemia, pues, como ya señalaba al comienzo de 
este texto, se ha híper desarrollado la creación de arte "desde el hogar". Esta situación invita a potenciar la creatividad, que siempre será bienvenida para todos los aspectos sociales. Cuando se habla de danza y sociedad no puedo dejar de pensar en etnoescenología (Pradier, 1997; Sapiain, 2015), puesto que la vinculación entre la obra de arte y las circunstancias sociales que envuelven a su creador es directa y estrecha. Esta unión permite que en el repertorio de un autor siempre habiten caracteres identificativos de mismo, pudiendo señalar, en cierto modo, el contexto social vivido durante el proceso creativo o, en su defecto, detectando los valores que defiende en su mensaje conceptual.

Ahora, un año después de la creación de la obra, puedo ver cómo este proceso creativo, además de cumplir su función laboral, funcionó como progreso de auto-terapia para sobrellevar el momento. Una relación donde mi "Yo" creador encontró en la pandemia una inspiración, una temática compleja e interesante, repleta de matices y contenido atractivo, el cual observaba con gran interés desde mi ventana; pero al mismo tiempo, necesitaba narrar mis experiencias como persona afectada por el virus: ahí es donde mi "Yo" artista se pudo apoyar para seguir adelante.

Este mismo proceso ocurrió en el trabajo con los bailarines; la decisión de aplicar la realidad social de los intérpretes a la obra ayudó plenamente en la consolidación emocional del mensaje. De este modo, pude salvar la distancia entre países y la separación física entre todos los componentes de la creación, encontrando un método para poder realizar con éxito un proceso creativo "a distancia".

\section{Referencias}

Gómez García, M. (2001). Escritura teatral: de las vanguardias al futuro. Monteagvdo, $3^{\mathrm{a}}$ Época, n. ${ }^{\circ}$ 6, Pp. 53-56. Recuperado de < https://revistas.um.es/monteagudo/article/view/77721>.

Pradier, J. M. (1997). Etnoescenología: la profundidad de las emergencias. Cuadernos de Teatro, Buenos Aires, Instituto de las Artes del Espectáculo, Facultad de Filosofía y Letras, Universidad de Buenos Aires, n. ${ }^{\circ} 11$, pp. 49-50.

Sapiain, C. (2015). El objeto de la etnoescenología frente al predominio del modelo escénico occidental. Revista el Sótano, n. ${ }^{\circ}$ 5, pp. 33-36. Recuperado de $<$ https://www.yumpu.com/es/document/read/15813299/el-objeto-de-investigacion-dela-etnoescenologia-frente-el-sotano/5>.

Duncan, I. (2016). Mi vida. L. Calvo (traducción). Buenos Aires: Editorial Losada. 


\section{| Nota biográfica |}

Manuel Garzón Albarrán es licenciado en Coreografía e Interpretación de la Danza y Máster Universitario en Artes escénicas por la Universidad Rey Juan Carlos de Madrid, actual doctorando en la Universidad Complutense de Madrid. Complementa su formación en el Royal Ballet de Londres, Ballet del Teatro Alla Scala de Millán y la Scuola di danza, Teatro dell'Opera di Roma. Durante 15 años compagina su carrera de intérprete de danza con la docencia y la coreografía, colaborando con varias compañías de danza nacionales e internacionales. Participa como bailarín y coreógrafo en reconocidos festivales internacionales como Festival Internacional de Ballet de la Habana (Cuba), Encuentro Nacional de Danza Contemporánea de Río Grande del Norte (Brasil), Festival de Invierno de Campiña Grande (Brasil), Festival Internacional de Danza de Miami, Festival Internacional de Danza de Santo Domingo (República Dominicana).

Durante 12 años ha sido docente titular del grado en Artes Visuales y Danza (URJC) y del Instituto Superior de Danza "Alicia Alonso" (Madrid). Actualmente trabaja en reputados centros de formación con bailarines de élite. Ha participado como jurado de certámenes de danza y coreografía. Entre su obra coreográfica se incluyen creaciones de danza clásica y contemporánea, videodanza y danza teatro.

Su línea de investigación se centra en los procesos creativos en danza y el papel de las emociones en la creación. Ha intervenido como comunicador en varios seminarios internacionales de investigación científica como la Rusian State University Named After A.N. Kosygin (Rusia), Vaganova Ballet Academy (Rusia) y Faculty of Arts and Humanities of Universidade de Coimbra (Portugal), entre otros; exponiendo investigaciones sobre la matriz de Historia de la Danza y la composición coreográfica. 